\title{
Transdermal Fentanyl Poisoning the Traps!
}

\begin{abstract}
Fentanyl is a potent opioid, whose analgesic action is 100 times more potent than morphine, used in the treatment of moderate to severe chronic pain. It acts on the $\mu$ receptors at the spinal level, supraspinal and around generating analgesia and sedation.

The placing on the market of a device delivering fentanyl transdermal (fentanyl patch), potentially lethal same low dose, since a $25 \mu \mathrm{g}$ patch per hour is equivalent to $90 \mathrm{mg}$ of morphine per day, led to numerous requirements, including the safety of the system depends on the conditions of its use.

We present a case of transdermal fentanyl overdose in a 18 years old patient brought by her mother to altered state of consciousness complicated respiratory arrest. A physical examination, two patches, Duragesic ${ }^{\circledast}(25 \mu \mathrm{g} / \mathrm{h})$ were found at the lumbosacral region. The purpose of this article is to highlight the pitfalls that can represent this patch, attract the attention of the clinician on adverse events associated with its use, to show that getting an early diagnosis can improve prognosis with review of the literature on fatal cases secondary to its use.
\end{abstract}

\section{A Salmi, A Métali, M Slimani and D Messaif}

\author{
Department of Medical and Surgical \\ Emergencies, University Hospital Center \\ Mustapha (Pr.M.Guerinik), Algiers, Algeria
}

\section{Corresponding author: A Salmi}

Department of and Surgical Emergencies, University Hospital Center Mustapha

(Pr.M.Guerinik), Algiers, Algeria.

\section{salmi_amine@yahoo.fr}

Tel: 0663503399

Citation: A Salmi, A Métali, M Slimani, et al. Transdermal Fentanyl Poisoning the Traps!. J Med toxicol clin forensic med. 2016, 1:2.

\section{Introduction}

Transdermal fentanyl (TDF) exists since 1991, with several presentations (12 mcg/hour, $25 \mathrm{mcg} /$ hour, $50 \mathrm{mcg} /$ hour, $75 \mathrm{mcg} / \mathrm{h}$ and $100 \mathrm{mcg} / \mathrm{h})$

It has two drug release modes: tank system and matrix system, enabling stable and sustained release of the active ingredient, which is ideal for the relief of chronic pain. Its soluble nature enables a wide distribution in different body compartments, in particular the blood-brain barrier [1]. When administered transdermally, the bioavailability is excellent (92\%) [2].

The TDF should be left in place for a period of three days, the equivalent of 72 hours.

The abuse of this drug is responsible for grave consequences, the most classic is respiratory depression, but a fatal outcome is possible.

\section{Case Presentation}

We report the case of a young patient KB 18 years old without medical history, admitted to medical emergencies for altered state of consciousness sudden onset, evolving in a context afebrile.

On admission, the patient was unconscious, scorée 8 on the Glasgow Coma Scale, isocoriques reactive pupils. Cardiovascular examination revealed a steady pace, slow (cardiac frequency $=54$ / '), a blood pressure $120 / 75 \mathrm{mmHg}$. Respiratory level, the patient was dyspneic with low $\mathrm{SPO}_{2}$ (85\% on room air). The remainder of the physical examination was unremarkable.
The research of toxic products in blood and urine level was negative.

During his exploration, the patient was breathing pauses, justifying orotracheal intubation.

Before clinical worsening, the mother says that her daughter had used the day before, two patches of TDF ( 25 micrograms $/ h$ ) for joint pain, without medical advice, which were found in the lumbar region.

The management was symptomatic, preceded by the withdrawal of two patches. The extubation was then possible to 48 hours after admission, and the patient was released on the 7th day.

\section{Discussion}

One of the problems posed by this poisoning is its unfamiliarity.

Indeed, small and transparent aspects of these patches (Figure 1), making detection difficult. On the other hand, negativity toxicology results by conventional techniques is a real trap for the clinician, which can confuse the clinical situation of whose early diagnosis is a key to the success of the management, of where interest to be vigilant, to partially explained clinical presentations, conducting a physical examination as complete as possible.

Given the difference in the transdermal patches of other opioids, other techniques (gas or liquid chromatography and mass spectrometry analysis) are required for diagnosis, since the standard tests detect only natural morphine derivatives 


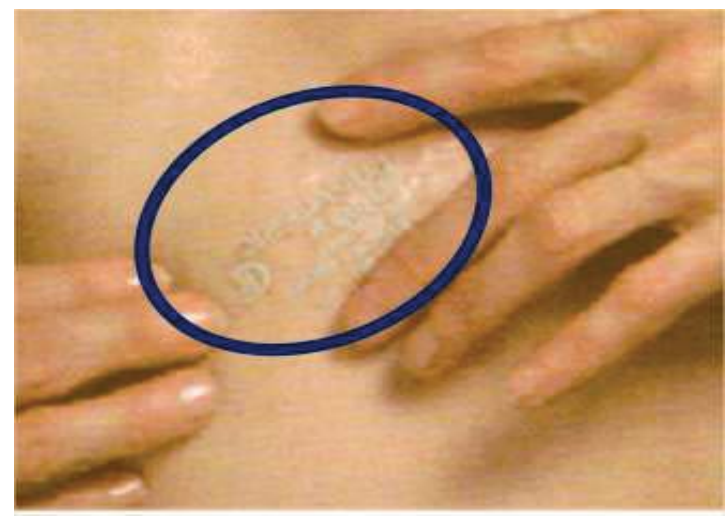

Figure 1

Transparent transdermal fentanyl.

(morphine, codeine).

All these difficulties explain the specific treatment delay, by antagonizing.

A search was conducted with the objective to identify cases of poisoning TDF, voluntary or not, fatal or not, using the following keywords: Transdermal fentanyl patch, fentanyl patch overdose, fatal fentanyl patch, patch fentanyl overdose, Deaths fentanyl patch.

Eighty-one death were recorded between 1990 and 2012 (43 men, 20 women, and 18 are of unknown gender). The median age of deceased persons was 39 years (1-84 years). The main cause of death was accidental, and this because of abuse of TDF or its misuse. [3]

In 1997, Hardwick Jr. and WE al published the case of a child aged 2 years victim of an accidental poisoning TDF, who slept with her grandmother, complicated by respiratory depression, whose evolution was favorable [4]. During the same year, Edinboro L. and al. described an overdose of fentanyl patches to many in an elderly 83 year patient, who used it to pain due to cancer, whose evolution was fatal. [5]

C. Kramer and al. in 2000 reported another case of poisoning TDF whose evolution was fatal. It was a 30 year old patient who used two transdermal fentanyl patches, one of which was placed in the buccal cavity, short intubation, and the other at the right thigh [6]. Three other cases were published by Moon JM. and al. In 2011, two patients had used fentanyl patch without medical advice.

The three patients had respiratory distress, whose evolution was favorable [7].

Other routes of administration of fentanyl patch used abusively were published. So Tharp AM. and al. published an article in 2004 in four patients died from the abuse of the patch fentanyl intravenously. [8] Teske J. and al. described in 2006 describes the case of an infant aged one year died following accidental ingestion of a fentanyl patch [9]. 2008 Karen L. and al. reported a series of seven patients who died after taking the oral fentanyl patch. [10] Thomas S. and al. reported another case of ingestion of the fentanyl patch in a patient of 42 years whose evolution was fatal [11].

The cases reported in the literature are mostly accidental deaths, so a potentially preventable situation. For that its use must be under medical prescription, respecting the dosage (typically a patch every 72 hours), and avoiding, especially during sleep, frequent physical contact. Recall the case of the child cited by WE Hardwick Jr. and al. [4] .Finally, to avoid accidental ingestion, especially in children, a used patch, the patch must be folded on itself: Used patches still contain significant amounts of fentanyl and place it in the supplied recovery system, place it out of reach of children and return it to the pharmacy.

The effectiveness of these transparent Stamp outside the patch site, the nature very adhesive, small size, and the accumulation of a long half-life molecule, are all risk factors that contribute to an increase users, and expose the physician to misdiagnosis. For this, the clinician who practices at the service of medical emergencies in particular, must be vigilant in making a careful examination of the skin and all body parts, without omitting the oral cavity, in search of one or multiple patches, enabling rapid diagnosis, initiate timely antagonizing and symptomatic treatment, and avoiding the prescription of unnecessary additional tests that will only delay the therapeutic management.

\section{Conclusion}

It is essential that prescribers, patients and family members receive information on the safe use of this product, in particular, the dangers associated with the application of multiple patches which can result in the release of potentially toxic doses or death.

Our case is added to the published cases with diagnostic difficulties.

Given its severity, acute intoxication by the transdermal Fentanyl, more and more frequent, should alert the clinician should keep in mind that this poisoning is possible, warranting careful clinical examination to detect these transparent patches, and provide as much information to better guide the diagnosis and analytical methods, to be used by laboratories.

Anyway, in case of accidental exposure, immediate medical consultation is the rule.

\section{Conflicts of Interest}

On behalf of all authors, the corresponding author states that there is no conflict of interest. 


\section{References}

1 Nelson L, Schwaner R (2009) Transdermal fentanyl: Pharmacology and toxicology. J Med Toxicol 5: 230-234.

2 Muijers R, Wagstaff AJ (2001) Transdermal fentanyl: An updated review of its pharmacological properties and therapeutic efficacy in chronic cancer pain control. Drugs 61: 2289-2307.

3 Pierre-André Dubé (2012) Bulletin d'information toxicologique, équipe de toxicologie clinique de l'Institut national de santé publique du Québec et du Centre antipoison du Québec 28.

4 Hardwick WE Jr, King WD, Palmisano PA (1997) Respiratory depression in a child unintentionally exposed to transdermal fentanyl patch. South Med J 90: 962-964.

5 Edinboro LE, Poklis A, Trautman D, Lowry S, Backer R, et al. (1997) Fatal fentanyl intoxication following excessive transdermal application. J Forensic Sci 42: 741-743.
6 Kramer C, Tawney M (1998) A fatal overdose of transdermally administered fentanyl. J Am Osteopath Assoc 98: 385-386.

7 Moon JM, Chun BJ (2011) Fentanyl Intoxication Caused by Abuse of Transdermal Fentanyl. J Emerg Med 40: 37-40.

8 Tharp AM, Winecker RE, Winston DC (2004) Fatal intravenous fentanyl abuse: Four cases involving extraction of fentanyl from transdermal patches. Am J Forensic Med Pathol 25: 178-181.

9 Teske J, Weller JP, Larsch K, Tröger HD, Karst M (2007) Fatal outcome in a child after ingestion of a transdermal fentanyl patch. Int J Legal Med 121: 147-151.

10 Woodall KL, Martin TL, McLellan BA (2008) Oral abuse of fentanyl patches (Duragesic): Seven case reports. J Forensic Sci 53: 222-225.

11 Thomas S, Winecker R, Pestaner JP (2008) Unusual fentanyl patch administration. Am J Forensic Med Pathol 29: 162-163. 